\title{
UMA ANÁLISE SOBRE A SELETIVIDADE DA JUSTIÇA CRIMINAL ${ }^{1}$
}

ANALYSIS ON THE SELECTIVITY OF CRIMINAL JUSTICE

Elaine Maria Silveira RITOSSA ${ }^{2}$

André Luis Jardini BARBOSA ${ }^{3}$

ISSUE DOI: $10.21207 / 2675-0104.2018 .766$

\section{RESUMO}

O presente artigo tem como objetivo analisar de maneira sintética de que forma um dos episódios mais sombrios de nossa história, a escravidão, mostra seus reflexos hodiernamente, a partir de uma análise da construção do Estado Democrático de Direito e do advento de teorias punitivistas, como o Direito Penal do Inimigo, ocasionando assim uma latente seletividade racista da justiça criminal brasileira.

Palavras-chave: Racismo. Seletividade. Direito Penal do Inimigo.

\section{ABSTRACT}

The present article aims to analyze in a synthetic way how one of the darkest episodes in our history, slavery, shows its reflexes today, based on an analysis of the construction of the Democratic State of

\footnotetext{
${ }^{1} \mathrm{O}$ presente artigo sintetiza a monografia de conclusão da pesquisa, realizada para o Programa Interno de Bolsas de Iniciação Científica (PIBIC 2017-2018) da Faculdade de Direito de Franca (FDF), Franca/SP.

${ }^{2}$ Discente da Faculdade de Direito de Franca (FDF), Franca/SP. Bolsista do Programa Interno de Bolsas de Iniciação Científica (PIBIC 2017-2018).

${ }^{3}$ Graduado em Direito pela Faculdade de Direito de Franca (2000), possui os Títulos de Especialista em Direito Processual Penal pela Escola Paulista da Magistratura, de Mestre em Direito pela Universidade Estadual Paulista - UNESP - campus Franca (2008) e de Doutor em Direito pela Faculdade Autônoma de Direito/FADISP. Exerce o cargo de Delegado de Polícia do Estado de São Paulo. Tem experiência na área de Direito, com ênfase nas áreas de Direito Penal, Direito Processual Penal, Legislação Penal Especial, Direito Constitucional, Direito Administrativo e Medicina Legal. É Professor das cadeiras de Investigação Policial e Inquérito Policial da Academia de Polícia Doutor Coriolano Nogueira Cobra.
} 
Law and the advent of punitive theories, such as the Criminal Law of the Enemy, thus causing a latent racist selectivity on the brazilian criminal justice.

Keywords: Racism. Selectivity. Criminal Law of the Enemy.

\section{INTRODUÇÃO}

O presente artigo científico tratará de uma temática demasiadamente polêmica e atualíssima no Direito, principalmente quando verificada a conjuntura brasileira: o Direito Penal do Inimigo na PósModernidade.

O Direito Penal do Inimigo, teoria formulada por Gunther Jakobs defende que, certas pessoas, por serem inimigas da sociedade (ou do Estado), não detém todas as proteções penais e processuais penais que são dadas aos demais indivíduos ${ }^{4}$. Tal teórica é demasiadamente controversa principalmente se analisado o paradigma do Estado Democrático de Direito.

O Estado Democrático de Direito, ou como é comumente chamado, "Estado de Direito", é uma forma de organização do Estado que tem como um de seus pilares estruturantes a defesa do princípio da dignidade da pessoa humana. Por exemplo, quando se observa a Constituição Federal do Brasil, em seu artigo $1^{\circ}$, onde é tratado os fundamentos da República Federativa do Brasil, tem-se ${ }^{5}$ :

Art. $1^{\circ}$ A República Federativa do Brasil, formada pela união indissolúvel dos Estados e Municípios e do Distrito Federal, constitui-se em Estado Democrático de Direito e tem como fundamentos:

I - a soberania;

II - a cidadania

III - a dignidade da pessoa humana;

IV - os valores sociais do trabalho e da livre iniciativa;

V - o pluralismo político.

Parágrafo único. Todo o poder emana do povo, que o exerce por meio de representantes eleitos ou diretamente, nos termos desta Constituição. (Grifo nosso).

\footnotetext{
${ }^{4}$ GOMES, Luiz Flávio. Direito Penal do Inimigo (ou inimigos do Direito Penal). Disponível em: http://conteudojuridico.com.br/artigo,direito-penal-do-inimigo-ou-inimigos-do-direitopenal,29698.html

5 BRASIL. Constituição da República Federativa do Brasil. Disponível em: http://www.planalto.gov.br/ccivil_03/constituicao/constituicaocompilado.htm
} 
Pela teórica de Jakobs, determinados sujeitos teriam suas garantias de direito material e também processuais relativizadas. Ora, claramente isso afronta os princípios de dignidade de forma frontal e muito profundamente. Para se ter ideia de como o Direito Penal do Inimigo é completamente contrário ao Estado Democrático, vale destacar o que dispõe o artigo $5^{\circ}$, LIV, da Constituição Federal: "LIV - ninguém será privado da liberdade ou de seus bens sem o devido processo legal;"”.

Quando é relativizada garantias de Direito material ou processual de um sujeito, resta bastante evidente de que não está sendo respeitado o due process of law e, portanto, não estão sendo observadas, por conseguinte, as garantias fundamentais do acusado. Todavia, por mais que a legislação penal vigente em nosso território nacional, em tese, garanta ao acusado que seus direitos fundamentais serão respeitados ao longo da persecução penal, na prática não é o que verdadeiramente acontece.

Para tanto, antes de mais nada, o presente trabalho, para que seja possível de se compreender a ratio da incidência do Direito Penal do Inimigo na sociedade brasileira, vai realizar um verdadeiro resgaste histórico de pontos fulcrais na formação social e histórica não só do Brasil, mas também do povo brasileiro. Para tanto, este artigo científico utilizará do método dedutivo, saindo da premissa maior, qual seja, demonstrando como se deu, em síntese, a formação histórica do povo brasileiro e do Brasil, para chegar a conclusões em situações mais específicas, como por exemplo na aplicação do Direito Penal na atualidade brasileira.

Exposto isso, o presente trabalho fará outro resgaste histórico das formas de organização do Estado, passando pelo Estado Liberal Clássico, passando pelo Estado de Bem-Estar Social de Keynes até a consolidação do Estado Democrático de Direito, para que seja demonstrada a enorme importância do modo de organização estatal sobre as matérias cotidianas do povo em geral. Nesse mesmo momento do artigo, o trabalho também exporá pontos fundamentais da teoria do Direito Penal do Inimigo para que seja vislumbrado com maior profundidade o objeto de estudo da pesquisa.

Por fim, no último capítulo do trabalho, será tratada a incidência do Direito Penal do Inimigo, na sociedade brasileira, na vigência da PósModernidade. Esse ponto é bastante importante justamente porque a PósModernidade traz em seu bojo o discurso de desconstrução e construção de novos paradigmas a todo momento, onde é posto em xeque os paradigmas consolidados e, por conseguinte, esse fenômeno engendra uma considerável instabilidade e insegurança. Nesse sentido, por conta desse 
sentimento de insegurança, a Teoria do Direito Penal do Inimigo ganha bastante fôlego.

Para a elaboração do artigo científico serão utilizadas obras de referência no assunto. Além das obras escritas, também serão utilizadas revistas e artigos eletrônicos de referência no assunto.

\section{RESGATE HISTÓRICO DA FORMAÇÃO SOCIAL E HISTÓRICA DO BRASIL E DO POVO BRASILEIRO}

Um dos pontos mais importantes de se ressaltar para compreender a Teoria do Direito Penal do Inimigo nos dias de hoje é, antes de mais nada, é estudar e compreender com profundidade do período escravista no Brasil.

Tal período é importante porque, durante o período do modo de produção escravista, no Brasil, havia a separação muito evidente de dois "tipos" de pessoa: os cidadãos e os não cidadãos. Esse conceito é demasiadamente relevante para Jakobs e para sua teoria.

Durante a escravidão haviam os senhores de engenho e os trabalhadores livres e, de outro lado, os trabalhadores escravos negros. Eis o ponto importante: os escravos não eram lidos pela sociedade como sujeitos de direito. Pelo contrário, os escravos eram comercializados e no tratamento, o escravo era visto como um bem onde o senhor de engenho exercia seu domínio. Isto é, o escravo era uma "coisa".

"Coisa" aqui entende-se a "coisa" do mesmo modo que o Código Civil trata. Não como uma aberração, mas como um bem o qual se tem a propriedade. Nesse diapasão, portanto, têm-se que os escravos, de forma alguma, eram sujeitos de direito ou possuíam personalidade jurídica. Sobre o instituto da personalidade jurídica a professora Mariana Armond Dias Paes em sua obra "sujeitos da história sujeitos de direitos: personalidade jurídica no Brasil escravista (1860-1888)" 6 , elucida de forma brilhante:

A personalidade jurídica é um instituto extremamente importante para o direito, pois é pelo seu reconhecimento que um ente adquire o status de sujeito de direito. A um ente sem personalidade jurídica não se atribui direitos. Dentre os entes dotados de personalidade

\footnotetext{
${ }^{6}$ PAES, Mariana Armond Dias. Sujeitos da história, sujeitos de direitos: personalidade jurídica no Brasil escravista (1860-1888). Tese de Mestrado apresentada à Universidade de São Paulo. São Paulo, 2014.
} 
jurídica, há uma variação da extensão dos direitos que são reconhecidos a cada um deles.

Uma das perspectivas mais interessantes para compreensão desse fenômeno é a análise de fontes históricas. Uma fonte importante para tentarmos, na atualidade, materializar como se dava o trato dos escravos à época da escravidão, é por meio da Literatura. Nesse momento histórico do Brasil, um dos autores literários mais críticos à barbárie do que foi a escravidão é o genial Machado de Assis.

Em uma cena clássica criada em seu livro "Memórias Póstumas de Brás Cubas", onde Brás Cubas sobe em cima de seu escravo, Prudêncio, bate nele e monta como se o escravo fosse seu "cavalinho", como se fosse um brinquedo. A única coisa que Prudêncio podia fazer é reclamar de dor, dizendo "Ai nhonhô".

Em outras duas obras, mas dessa vez sob a forma de contos, "O caso da Vara" e "O pai contra mãe", Machado de Assis deixa evidente a forma de punição que era aplicada aos escravos, como se pode ver no excerto destacado do conto "O caso da Vara" 7 :

(...) Uma destas, estúrdia, obrigada a trejeitos, fez rir a uma das crias de Sinhá Rita, que esquecera o trabalho, para mirar e escutar o moço. Sinhá Rita pegou de uma vara que estava ao pé da marquesa, e ameaçou-a: - Lucrécia, olha a vara! A pequena abaixou a cabeça, aparando o golpe, mas o golpe não veio. Era uma advertência; se à noitinha a tarefa não estivesse pronta, Lucrécia receberia o castigo do costume. (...)

A "vara" aqui é entendida como forma de puniçãoaos escravos que desobedeciam a seus senhores. Já no conto "O pai contra a mãe", Machado também explicita a punição cruel dos escravos"

Há meio século, os escravos fugiam com frequiência. Eram muitos, e nem todos gostavam da escravidão. Sucedia ocasionalmente apanharem pancada, e nem todos gostavam de apanhar pancada. Grande parte era apenas repreendida; havia alguém de casa que servia de padrinho, e o mesmo dono não era mau; além disso, o sentimento da propriedade moderava a ação, porque dinheiro também dói. A fuga repetia-se, entretanto.

\footnotetext{
${ }^{7}$ ASSIS, Machado de 0 conto da vara. Disponível em: http://www.dominiopublico.gov.br/download/texto/bv000219.pdf ${ }^{8}$ ASSIS, Machado de. O pai contra a http://www.dominiopublico.gov.br/download/texto/bv000245.pdf

mãe. Disponível em:
} 
"Dinheiro também doi". Verifica-se aqui claramente que a preocupação dos senhores para com o escravo era pura e simplesmente patrimonial. Tanto é que as penas aplicadas são bastante cruéis e avançaram no sentido de que as questões relacionadas à fuga de escravos foram tuteladas no Código Criminal do Império do Brasil, no capítulo concernente aos crimes contra a segurança interna do Império e da tranquilidade pública, caracterizando a Insurreição nos art.113 ao 115 como crime punível à morte, à galés perpétuas e açoites ${ }^{9}$.

Quando, no Brasil, os movimentos abolicionistas começaram a ganhar mais força, às vésperas da abolição da escravidão, são editadas duas leis: Lei Eusébio de Queirós e a Lei de Terras. Ambas as legislações prejudicaram demasiadamente a inserção do negro, ex-escravo, na sociedade. Isso porque, por mais que em 1888, tenha sido editada a Lei Áurea que pôs fim a escravidão, a cultura escravista desenvolvida no Brasil indubitavelmente não foi extinta em 1888.

Dessa maneira, surgem assim discursos onde brancos livres, para atacar negros, ex- escravos, embasam seu sucesso sob o argumento da "superioridade". Nesse sentido, explicita a professora Rosa Del Omo ${ }^{10}$ :

A superioridade - tal como formulava o evolucionismo - era o resultado da seleção natural transmitida geneticamente. Os seres "inferiores" (leia-se: não proprietários) estavam obrigados à obediência e submissão por sua inferioridade (...) O criminoso, o anti-social e o socialmente necessitado pertenciam a uma raça inferior em relação à raça 'respeitável' e podiam ser reconhecidos por sinais tais como a medida do crânio e outras formas igualmente simples

No entanto, isso não é um processo isolado no Brasil. Durante o século XIX inteiro as teorias cientificistas ganharam muita força, entre elas o Darwinismo que gerou o "Darwinismo Social". Para entender ainda mais o que seria esse fenômeno, retomemos a Machado de Assis, só que dessa vez no livro "Quincas Borba". Neste livro, Machado ironiza as teorias cientificistas do século XIX, em especial o Darwinismo Social, onde, o personagem Quincas Borba cria uma teoria chamada "Humanitismo", onde "o mais forte" ou "superior" sai vencedor em todos os aspectos da vida":

\footnotetext{
${ }^{9}$ RODRIGUES, Renata. Uma análise do ranço da escravidão no Brasil. Disponível em: https://jus.com.br/artigos/22748/uma-analise-do-ranco-da-escravidao-no-brasil/1

${ }^{10}$ DEL OLMO, Rosa. A América Latina e sua criminologia, $1^{a}$ ed. Rio de Janeiro: Revan, 2004. pp. 43-44.

${ }^{11}$ ASSIS, Machado de. Quincas Borba. Disponível em: http://www.dominiopublico.gov.br/download/texto/bv000243.pdf
} 
- Bem, irás entendendo aos poucos a minha filosofia; no dia em que a houveres penetrado inteiramente, ah! nesse dia terás o maior prazer da vida, porque não há vinho que embriague como a verdade. Crê-me, o Humanitismo é o remate das cousas; e eu que o formulei, sou o maior homem do mundo. Olha, vês como o meu bom Quincas Borba está olhando para mim? Não ele, é Humanitas... - Mas que Humanitas é esse? - Humanitas é o princípio. Há nas cousas todas certa substância recôndita e idêntica, um princípio único, universal, eterno, comum, indivisível e indestrutível, - ou, para usar a linguagem do grande Camões

(...) Não há morte. O encontro de duas expansões, ou a expansão de duas formas, pode determinar a supressão de uma delas; mas, rigorosamente, não há morte, há vida, porque a supressão de uma é princípio universal e comum. Daí o caráter conservador e benéfico da guerra. Supõe tu um campo de batatas e duas tribos famintas. As batatas apenas chegam para alimentar uma das tribos, que assim adquire forças para transpor a montanha e ir à outra vertente, onde há batatas em abundância; mas, se as duas tribos dividirem em paz as batatas do campo, não chegam a nutrir-se suficientemente e morrem de inanição. A paz nesse caso, é a destruição; a guerra é a conservação. Uma das tribos extermina a outra e recolhe os despojos. Daí a alegria da vitória, os hinos, aclamações, recompensas públicas e todos os demais efeitos das ações bélicas. Se a guerra não fosse isso, tais demonstrações não chegariam a darse, pelo motivo real de que o homem só comemora e ama o que lhe aprazível ou vantajoso, e pelo motivo racional de que nenhuma pessoa canoniza uma ação que virtualmente a destrói. Ao vencido, ódio ou compaixão; ao vencedor, as batatas. - Mas a opinião do exterminado? - Não há exterminado. Desaparece o fenômeno; a substância é a mesma. Nunca viste ferver água? Hás de lembrar-te que as bolhas fazem-se e desfazem-se de contínuo, e tudo fica na mesma água. Os indivíduos são essas bolhas transitórias. - Bem; a opinião da bolha... - Bolha não tem opinião. Aparentemente, há nada mais contristador que uma dessas terríveis pestes que devastam um ponto do globo? E, todavia, esse suposto mal é um benefício, não só porque elimina os organismos fracos, incapazes de resistência, como porque dá lugar à observação, à descoberta da droga curativa. A higiene é filha de podridões seculares; devemola a milhões de corrompidos e infectos. Nada se perde, tudo é ganho. Repito, as bolhas ficam na água. Vês este livro? É D. Quixote. Se eu destruir o meu exemplar, não elimino a obra que continua eterna nos exemplares subsistentes e nas edições posteriores. Eterna e bela, belamente eterna, como este mundo divino e supradivino.

Esse discurso de superioridade tomou a sociedade brasileira, como toma a ainda toma até os dias hodiernos. Dessa maneira, aqueles que são considerados não cidadãos hão de ser julgados por um outro método punitivo, em uma outro método de penalização, o que engendra, sem sobra 
de dúvidas, até os dias de hoje, a sombra do Direito Penal do Inimigo, conforme explica o Guilherme Alves Cortez da Fonseca ${ }^{12}$ :

\begin{abstract}
Note-se ainda que, nesses regimes, a desigualdade de tratamento penal entre os "cidadãos" e os "inimigos" era nítida: os inimigos do Estado eram submetidos a um sistema penal paralelo, composto por tribunais especiais inquisitoriais. O sistema penal formal desses regimes, previsto em lei, era tímido e não dava a dimensão exata das atrocidades que eram cometidas. Na prática, operava um sistema penal subterrâneo, sem lei e, portanto, sem qualquer tipo de limite.
\end{abstract}

Por conta dessa diferença de tratamento que possui origens históricas, é imprescindível o estudo da escravidão no Brasil para entender o Direito Penal do Inimigo nos dias atuais na sociedade brasileira.

\title{
O ESTADO DEMOCRÁTICO DE DIREITO E O DIREITO PENAL DO INIMIGO
}

Um dos pontos de partida para entender o Estado Democrático Brasileiro é a crise da bolsa de Nova Iorque em 1929. Isso porque tal acontecimento gerou no mundo todo crises econômicas que engendraram a queda do Estado Liberal Clássico. A queda da bolsa colocou em xeque não só a organização de Estado em torno do laissez-faire, laissez-passer e a mão invisível, como também a ideologia do liberalismo econômico. Vale ressaltar que a experiência brasileira, per si, não deixa evidente que tivemos uma experiência clássica do Estado Liberal e, sim, que houve apenas influências.

Como consequência da queda do Estado Liberal, há o advento do Estado Intervencionista keynesiano, onde uma boa síntese pode ser encontrada no lema "do berço ao túmulo". O Estado Keynesiano tinha como base o aprofundamento dos direitos e garantias fundamentais da população, a intervenção do Estado na economia e a geração de empregos.

O Brasil, na prática, também não teve em sua história o clássico Estado de Bem-Estar Social como teve a Europa e os Estados Unidos da América. Mas, contemporâneo ao Estado de Bem-Estar Social, no Brasil surgiram figuras como Getúlio Vargas, Juscelino Kubitscheck e os

${ }^{12}$ FONSECA, Guilherme Alves Cortes da. O Direito Penal do Inimigo e sua incidência na decretação de prisões preventivas e no regime disciplinar diferenciado. Disponível em: https://www.maxwell.vrac.puc-rio.br/26076/26076.PDF 
ditadores do Regime Militar que realizaram fortes intervenções estatais no que antes era considerado apenas de âmbito privado.

Por conta dos grandes gastos públicos, o Estado de Bem-Estar Social a entrar em crises profundas. Nesse contexto surge o Estado Democrático de Direito. Um marco interessante para análise do Estado de Direito é a Constituição Federal de 1988. Este último é muito importante por valorizar grandemente o princípio da dignidade da pessoa humana e por valorizar a igualdade material entre as pessoas, festejando a segunda geração de direitos fundamentais.

Nesse sentido, capítulos importantes da Constituição Federal demonstram que o Estado Brasileiro atuará para a defesa dos direitos fundamentais e da dignidade do cidadão, como o Título VIII da Constituição que é denominado "Da Ordem Social”, onde é tratado temas caros à população como Previdência Social. Outro ponto interessante de se colocar é que o artigo $3^{\circ}$ da Carta Política brasileira é alinhado ao constitucionalismo moderno, onde é claramente evidente a perspectiva de construção de um Estado Social:

\footnotetext{
Art. $3^{\circ}$ Constituem objetivos fundamentais da República Federativa do Brasil:

I - construir uma sociedade livre, justa e solidária;

II - garantir o desenvolvimento nacional;

III - erradicar a pobreza e a marginalização e reduzir as desigualdades sociais e regionais;

IV - promover o bem de todos, sem preconceitos de origem, raça, sexo, cor, idade e quaisquer outras formas de discriminação.
}

Fica muito evidente que os objetivos elencados para serem alcançados pela República possuem forte cunho social. Nesse diapasão ensinam Streck e Morais ${ }^{13}$ :

[...] a constituição do Brasil, que determina, no art. $3^{\circ} 27$, a construção do Estado Social, cujo papel cunhado pela tradição do constitucionalismo contemporâneo, "é o de promover a integração da sociedade nacional ou seja, " el proceso constantemente renovado de conversión de uma pluralidad em uma unidad sin perjucio de la capacidad de autodeterminación de lãs partes" (Manuel García-Pelayo). Integração esta quer, no caso brasileiro, deve dar tanto no nível social quanto no econômico, com a trans formação das estruturas econômicas e sociais. Conforme podemos depreender de seus princípios fundamentais, que consagram fins

\footnotetext{
${ }^{13}$ STRECK, Lênio Luiz; MORAIS, José Luís Bolzan. Ciência Política e Teoria Geral do Estado. Porto Alegre: Livraria do Advogado, 2000. 183
} 
sociais e econômicos em fins jurídicos, a Constituição de1988 é voltada à transformação da realidade brasileira.

Nessa esteira, para que o artigo científico recaia propriamente ao objeto de pesquisa, passar-se-á expor análises e conceitos sobre o Direto Penal do Inimigo e ficará explicito como esta teoria é diametralmente oposta à fundamentação do Estado Democrático de Direito.

O Direito Penal do Inimigo é uma teoria criada por Gunther Jakobs que, em poucas linhas, separa o Direito Penal em dois: o Direito Penal do Cidadão e o Direito Penal do Inimigo. Nesse sentido, diz o próprio autor da teoria ${ }^{14}$ :

O Direito Penal do Cidadão é o Direito de todos, o Direito Penal do inimigo é daqueles que o constituem como inimigo: frente ao inimigo, é só coação física, até chegar à guerra. Esta coação pode ser limitada em um duplo sentido. Em primeiro lugar, o Estado não necessariamente excluirá o inimigo de todos os direitos. Neste sentido, o sujeito submetido à custódia de segurança fica incólume em seu papel de proprietário de coisas. E, em segundo lugar, o Estado não tem por que fazer tudo que é permitido fazer, mas pode conter-se, em especial, para não fechar as portas a um posterior acordo de paz.

Nesse sentido, segundo Meliá, o Direito Penal do Inimigo constitui um combate do ordenamento jurídico aos indivíduos especialmente perigosos, que nada significam ${ }^{15}$. Segundo o professor e ministro do Superior Tribunal Federal Alexandre de Moraes, o Direito Penal do Inimigo representa uma verdadeira guerra cujo caráter limitado depende do quanto se teme com relação ao inimigo ${ }^{16}$.

Na concepção de Jakobs, o não-alinhado é um indivíduo que, não apenas de maneira incidental, em seu comportamento (criminoso grave) ou em sua ocupação profissional (criminosa e grave) ou, principalmente, por meio de vinculação a uma organização (criminosa), vale dizer, em qualquer caso de forma presumivelmente permanente, abandonou o direito e, por

\footnotetext{
${ }^{14}$ JAKOBS, Gunther. La ciência del derecho penal ante las exigências del presente. Bogotá. Universidad Externado de Colombia- Centro de invetigaciones de Derecho Penal Y Filosofia del Derecho. 2000, p.33.

${ }^{15}$ JAKOBS, Gunther. Direito Penal do Inimigo. Bogotá. Universidad Externado de Colombia- Centro de invetigaciones de Derecho Penal Y Filosofia del Derecho. 2000, p.33.

${ }^{16}$ MORAES, Alexandre Rocha Almeida de. A terceira velocidade do Direito Penal: o "Direito Penal do Inimigo". Dissertação apresentada à Pontifícia Universidade Católica de São Paulo como exigência para o grau de Mestrado. São Paulo, 2006.
} 
conseguinte, não garante o mínimo de segurança cognitiva do comportamento pessoal e o manifesta por meio de sua conduta ${ }^{17}$

Nessa esteira, define o próprio autor da teoria ${ }^{18}$ :

Para a definição do autor como inimigo do bem jurídico, segundo a qual poderiam ser combatidos já os mais prematuros sinais de perigo, embora isso possa não ser oportuno no caso concreto, devese contrapor aqui uma definição do autor como cidadão. O autor não somente deve ser considerado como potencialmente perigoso para os bens da vítima, como deve ser definido também, de antemão, por seu direito a uma esfera isenta de controle; e será mostrado que do status de cidadão podem se derivar limites, até certo ponto firmes, para as antecipações de punibilidade.

Sánchez sobre o inimigo de Jakobs ${ }^{19}$ :

O inimigo é um indivíduo que, mediante seu comportamento, sua ocupação profissional ou, principalmente, mediante sua vinculação a uma organização, abandonou o Direito de modo supostamente duradouro e não somente de maneira incidental. Em todo caso, é alguém que não garante mínima segurança cognitiva de seu comportamento pessoal e manifesta esse déficit por meio de sua conduta. (...) Se a característica do 'inimigo" é o abandono duradouro do Direito e ausência da mínima segurança cognitiva em sua conduta, então seria plausível que o modo de afrontá-lo fosse com o emprego de meios de asseguramento cognitivo desprovidos da natureza de penas.

No entanto, é muito controvertida a presente questão, pois, como o próprio professor Alexandre de Moraes explicita em sua tese de Mestrado $^{20}$, os críticos ao Direito Penal do Inimigo rebatem fortemente a teoria de Jakobs questionando: como será feita a separação do cidadão e do não-cidadão?

Além disso, os críticos à teoria do Direito Penal do Inimigo defendem que tal teoria é completamente contrária ao Estado de Direito, por desconsiderar o acusado "dito como perigoso" como um não-cidadão,

${ }^{17}$ MORAES, Alexandre Rocha Almeida de. A terceira velocidade do Direito Penal: o "Direito Penal do Inimigo". Dissertação apresentada à Pontifícia Universidade Católica de São Paulo como exigência para o grau de Mestrado. São Paulo, 2006.

${ }^{18}$ JAKOBS, Fundamentos do Direito Penal. São Paulo: Revista dos Tribunais, Trad. André Luís Callegari, 2003, p. 111

${ }^{19}$ SÁNCHEZ, Jesus-Maria Silva. A Expansão do Direito Penal: Aspectos da política criminal nas sociedades pós-industriais, São Paulo: Revista dos Tribunais, Série as Ciências Criminais no Século XXI - v. 11, Tradução: Luiz Otavio de Oliveira Rocha, 2002.

${ }^{20}$ MORAES, Alexandre Rocha Almeida de. A terceira velocidade do Direito Penal: o "Direito Penal do Inimigo". Dissertação apresentada à Pontifícia Universidade Católica de São Paulo como exigência para o grau de Mestrado. São Paulo, 2006. 
um não sujeito de direitos, lembrando que a Constituição Federal de 1988 estabelece como um dos fundamentos do Estado Democrático Brasileiro, em seu artigo $1^{\circ}$, a cidadania.

\section{O DIREITO PENAL DO INIMIGO NA REALIDADE BRASILEIRA ATUAL}

Por conta da escravidão, o Brasil possui enraizado o que é denominado como "ranço colonial". Isso é facilmente comprovado, quando analisado os dados carcerários nacionais. O Brasil é o quarto país que mais encarcera no mundo, segundo dados do Ministério da Justiça referentes ao primeiro semestre de 2014, totalizando uma população carcerária de 607.700 presos; destes, 67,1\% são negros, e oito em cada dez estudaram, no máximo, até o ensino fundamental

A maioria de encarcerados negros não é um mero golpe do destino. Pelo contrário, desde a época da escravidão os escravos negros foram colocados como "coisas", "bens" cujo domínio o senhor de engenho exercia. Após a alforria, os escravos se tornaram paisagem marginalizada das mais diversas localidades no país, sem direito à terra ou ao trabalho. A realidade se perpetuou e atualmente o Brasil está perto do podium das maiores populações carcerárias do mundo.

Segundo Zaffaroni, em especial na América Latina, o Direito Penal do Inimigo se manifesta principalmente em medidas de contenção de suspeitos colocados como "perigosos". Nesse sentido, se institucionaliza o denominado "direito penal de periculosidade presumida" 21 . Diante disso, o professor Zaffaroni arremata:

A característica mais destacada do poder punitivo latino-americano
atual em relação ao aprisionamento é que a grande maioria -
aproximadamente $3 / 4$ - dos presos está submetida a medidas de
contenção, porque são processados não condenados (...) tudo se
converteu em privação de liberdade sem sentença firme, apenas por
presunção de periculosidade (...) a medida cautelar é pena cautelar,
ou seja, por precaução, o poder punitivo é exercido condenando-se
materialmente todos os acusados a uma medida e revisando-se com
grande parcimônia essas condenações, num processo que se arrasta
anos a fio, com o intuito de verificar se corresponde a uma pena

${ }^{21}$ FONSECA, Guilherme Alves Cortes da. O Direito Penal do Inimigo e sua incidência na decretação de prisões preventivas e no regime disciplinar diferenciado. Disponível em: https://www.maxwell.vrac.puc-rio.br/26076/26076.PDF 
formal. O desencarceramento ou a cessação da prisão preventiva ou provisional representa uma absolvição, pois corresponde a quase todos os seus efeitos.

Segundo dados do Conselho Nacional do Ministério Público, em dados apresentados neste ano de 2018, os presos provisórios no Brasil, isto é, presos que não possuem nenhum tipo de condenação no processo o qual estão presos cautelarmente, já chegam a $40 \%$ da população carcerária, isto é, quase metade ${ }^{22}$. Diante desses dados, o professor Rômulo Moreira expõe $\mathrm{e}^{23}$ :

Estes números impressionam, traduzindo friamente uma tragédia nacional. Mostram que o cárcere ainda é concebido como prima ratio para a questão da violência e da segurança pública, quando deveria ser rigorosamente o contrário. É de Hulsman a seguinte afirmação: "Em inúmeros casos, a experiência do processo e do encarceramento produz nos condenados um estigma que pode se tornar profundo. Há estudos científicos, sérios e reiterados, mostrando que as definições legais e a rejeição social por elas produzida podem determinar a percepção do eu como realmente 'desviante' e, assim, levar algumas pessoas a viver conforme esta imagem, marginalmente. Vemo-nos de novo diante da constatação de que o sistema penal cria o delinquente, mas, agora, num nível muito mais inquietante e grave: o nível da interiorização pela pessoa atingida do etiquetamento legal e social.

A Pós-Modernidade, com sua quebra ferrenha de paradigmas, o seu questionamento sistemático sobre tudo e todos, conjuntamente com o modelo de globalização neoliberal acirra ainda mais a incidência de teorias como o Direito Penal do Inimigo devido à institucionalização da insegurança. Nesse sentido, ensina o professor Batista ${ }^{24}$ :

os saltos tecnológicos, que elevaram as telecomunicações à magnitude negocial e ao protagonismo político de que hoje desfrutam, também imprimem suas marcas: enquanto, anteriormente, germinaram instrumentos de proteção da intimidade e da vida privada, o novo sistema penal do Estado neoliberal, replicante do vigilantismo eletrônico, é extremamente invasivo e cultua a delação, cujo estatuto ético virou-se pelo avesso.

Sobre o papel da mídia nesse processo, ainda segue Batista:

\footnotetext{
${ }^{22}$ MOREIRA, Rômulo Andrade de. A realidade carcerária brasileira em números. Disponível em: http://justificando.cartacapital.com.br/2018/07/02/realidade-carceraria-do-brasil-em-numeros/

${ }^{23}$ MOREIRA, Rômulo Andrade de. A realidade carcerária brasileira em números. Disponível em: http://justificando.cartacapital.com.br/2018/07/02/realidade-carceraria-do-brasil-em-numeros/

${ }^{24}$ BATISTA, Nilo. Novas Tendências do Direito Penal. Rio de Janeiro: Revan, 2004, p. 83-85
} 


\begin{abstract}
Antes de mais nada, a mídia não apenas se adequou, mas colaborou definitivamente na expansão de uma mentalidade penal que imobiliza toda a riqueza e complexidade dos conflitos sociais na episteme binária e simplória do infracional: é assim que a questão da reforma agrária pode ser reduzida a delito contra a propriedade de integrantes do MST, por um lado, e aos 'excessos' policiais contra eles (chacinas) de outro. Ao processo de desmerecimento do setor público, funcional para a implementação das privatizações, correspondeu a criminalização midiática da vida política. No núcleo ideológico deste movimento está não apenas um discurso criminológico único - que assume preponderância e influência muito superior ao acadêmico, e cujas toscas contradições e inconsistências não encontram canal de questionamento - mas principalmente uma novidade perigosa: o exercício direto de funções características das agências policiais do sistema pena.
\end{abstract}

Portanto, se percebe que o próprio modo de produção capitalista, no seu rearranjo neoliberal, globalizante e pós-moderno vai contribuindo e muito - para uma grande incidência da Teoria do Direito Penal do Inimigo. Isso porque, por conta das grandes proporções tomadas pelos meios técnicos científicos-informacionais, a mídia, em sua grande maioria, muito conservadora, reproduz os preconceitos históricos, os ranços coloniais, e deixa cada vez mais arraigada a imagem do negro, pobre e periférico como um verdadeiro inimigo público.

\title{
5 CONSIDERAÇÕES FINAIS
}

Em síntese, como se verifica por todo o exposto, o Direito Penal do Inimigo pode ser compreendido, de forma muito plausível e razoável, uma forma de aplicação do Direito Criminal completamente contrária ao Estado Democrático de Direito. Isto porque o Direito Penal do Inimigo relativiza aquele que é entendido como o inimigo público como um sujeito de direito. Ou seja, o "inimigo" perde garantias processuais, materiais e constitucionais, a começar por não ser considerado um cidadão (ao menos na seara do Direto Criminal).

Outrossim, conforme exposto ao longo do trabalho, um dos marcos (senão o marco mais importante) do Estado Democrático de Direito brasileiro é a promulgação da Constituição Federal de 1988. A Constituição vigente bebe da fonte do neoconstitucionalismo, que festeja profundamente o princípio da dignidade da pessoa humana.

Um dos pontos mais interessantes da Constituição Federal é a positivação do artigo $5^{\circ}$, LIV, onde é mencionado o princípio do "devido 
processo legal". Isso é importantíssimo, pois, a Constituição ao garantir o devido processo legal, demonstra que o ânimo da sociedade, quando da promulgação da Carta Política, bem como do legislador constitucional, é de afastar os procedimentos criminais inquisitivos que aconteciam durante todo o regime civil militar. Por conseguinte, ao se afastar dos procedimentos inquisitivos, a Constituição Federal aproxima-se da teoria garantista do processo criminal.

Na direção contrária vai a Teoria do Direito Penal do Inimigo. Esta última ao afirmar que há um inimigo público e que, a depender do grau de "medo" que se tem desse inimigo as garantias fundamentais podem ser flexibilizadas, aproxima-se dos procedimentos inquisitoriais. Rasga-se o princípio da legalidade, da anterioridade legal, do in dubio pro reo, do promotor e juiz natural, do due process os law, entre outros tantos importantes direitos do acusado ou réu.

Ademais, o fenômeno da Pós Modernidade contribui - e muitopara o acirramento dos ânimos sociais e para uma pressão maior no sentido favorável à incidência do Direito Penal Inimigo na prática forense. Isso se dá por diversos motivos, entre eles: a institucionalização da insegurança, a banalização da vida por conta das relações demasiadamente líquidas e espetacularização da vida, haja vista diversos programas sensacionalistas que são transmitidos nos mais diversos canais de televisão.

A Pós-Modernidade também contribui pelo fato de que esta última prega insistentemente a quebra de paradigmas. Com efeito, o paradigma do garantismo penal, da processualística embasada na teoria neoconstitucional, também hão de ser "descontruídos" pela mentalidade pós-moderna, dando ensejo à incidência de novas teorias.

Outrossim, nesse contexto de reorganização do Estado, salientase que para o Direito Penal, a globalização e o neoliberalismo também possuem algumas influências negativas, haja vista que no mundo globalizado, de grande técnico científica-informacional, no paradigma da institucionalização da insegurança, por meio dos veículos de comunicação, as mentalidades da população são disputadas, de forma que a figura do inimigo público pode ser facilmente disseminada. Por fim, o modo de produção capitalista na sua organização neoliberal, que preza pelo Estado minimamente interventor, classicamente extingue direitos de toda ordem, inclusive os direitos e garantias criminais. 
ASSIS, Machado de. O conto da vara. Disponível em: http://www.dominiopublico.gov.br/download/texto/bv000219.pdf

O pai contra a mãe. Disponível em:

http://www.dominiopublico.gov.br/download/texto/bv000245.pdf

Quincas Borba. Disponível em:

http://www.dominiopublico.gov.br/download/texto/bv000243.pdf

BRASIL. Constituição da República Federativa do Brasil. Disponível em:

http://www.planalto.gov.br/ccivil_03/constituicao/constituicaocompilado.htm

BATISTA, Nilo. Novas Tendências do Direito Penal. Rio de Janeiro: Revan, 2004, p. 83-85

DEL OLMO, Rosa. A América Latina e sua criminologia, $1^{a}$ ed. Rio de Janeiro: Revan, 2004. pp. 43 44.

FONSECA, Guilherme Alves Cortes da. O Direito Penal do Inimigo e sua incidência na decretação de prisões preventivas e no regime disciplinar diferenciado. Disponível em:

https://www.maxwell.vrac.puc-rio.br/26076/26076.PDF

GOMES, Luiz Flávio. Direito Penal do Inimigo (ou inimigos do Direito Penal). Disponível em: http://conteudojuridico.com.br/artigo,direito-penal-do-inimigo-ou-inimigos-do-direitopenal,29698.html

JAKOBS, Gunther. Direito Penal do Inimigo. Bogotá. Universidad Externado de Colombia- Centro de invetigaciones de Derecho Penal Y Filosofia del Derecho. 2000, p.33.

Fundamentos do Direito Penal. São Paulo: Revista dos Tribunais, Trad. André

Luís Callegari, 2003, p. 111

La ciência del derecho penal ante las exigências del presente. Bogotá.

Universidad Externado de Colombia- Centro de invetigaciones de Derecho Penal Y Filosofia del Derecho. 2000, p.33.

MORAES, Alexandre Rocha Almeida de. A terceira velocidade do Direito Penal: o "Direito Penal do Inimigo". Dissertação apresentada à Pontifícia Universidade Católica de São Paulo como exigência para o grau de Mestrado. São Paulo, 2006.

MOREIRA, Rômulo Andrade de. A realidade carcerária brasileira em números. Disponível em: http://justificando.cartacapital.com.br/2018/07/02/realidade-carceraria-do-brasil-em-numeros/

PAES, Mariana Armond Dias. Sujeitos da história, sujeitos de direitos: personalidade jurídica no Brasil escravista (1860-1888). Tese de Mestrado apresentada à Universidade de São Paulo. São Paulo, 2014.

SÁNCHEZ, Jesus-Maria Silva. A Expansão do Direito Penal: Aspectos da política criminal nas sociedades pós-industriais, São Paulo: Revista dos Tribunais, Série as Ciências Criminais no Século XXI - v. 11, Tradução: Luiz Otavio de Oliveira Rocha, 2002 
STRECK, Lênio Luiz; MORAIS, José Luís Bolzan. Ciência Política e Teoria Geral do Estado. Porto Alegre: Livraria do Advogado, 2000. 183

RODRIGUES, Renata. Uma análise do ranço da escravidão no Brasil. Disponível em: https://jus.com.br/artigos/22748/uma-analise-do-ranco-da-escravidao-no-brasil/1 